\title{
Investigating the relationship between creativity and academic achievement of Malaysian undergraduates.
}

\begin{abstract}
The present study focused on investigating the relationship between creativity and academic achievement of Malaysian undergraduates who are studying TESL (Teaching English as a Second Language). Through random sampling, 100 students (46 males and 54 females) from different Universities in Malaysia were selected to participate in this study. As the research instruments, Cumulative grade point average (CGPA), and Nicolas Holt Creativity Test (NHCT) were used to measure the academic achievement and creative potential of students. Inferential statistics were utilized to analyze the data. The Pearson Correlation coefficient indicated a significant positive relationship between creativity and academic achievement of students. A significant gender differences were found between male and female students, their creativity and their academic achievement. Finally, the results of the study and their implications are discussed.
\end{abstract}

Keyword: Creativity; Academic achievement; Gender; Undergraduate students. 